\title{
Extent IEPs for Students under Categories of Disability have Behavior Intervention Plans Based on FBAs
}

\author{
Cindy Serfass, John W Maag* and Reece L Peterson \\ University of Nebraska, Lincoln, USA
}

\begin{abstract}
Behavior intervention plans developed from functional behavioral assessments are typically part of the individual education plans for students receiving special education services under the IDEA emotionally disturbed (ED) category. Recently, the number of students identified as other health impaired (OHI) has tripled since 1997, largely due to the inclusion of students with ADHD. Similar increases in students have occurred for the category of Autism. Students in both categories also display challenging behaviors. Therefore, the purpose of the present study was to determine whether students who displayed significantly challenging behaviors in the $\mathrm{OHI}$ and Autism categories had specific behavior intervention plans based on the results of functional assessment. Results indicated that even when students in the $\mathrm{OHI}$ and autism categories displayed substantial challenging behaviors, very few FBAs were conducted nor were ensuing BIPs developed. Implications for practice are discussed.
\end{abstract}

\section{Introduction}

Students who display persistent and severe challenging behaviors have traditionally been served under the federal category of Emotional Disturbance (ED) [1]. The primary methods for addressing these students' behavioral needs are through behavior intervention plans (BIPs) that were based on functional behavioral assessments (FBAs). These BIPs have been effective with students displaying a wide range of disabilities [2-5]. However, they typically appear in the individual education plans (IEPs) of students served under the ED category [6].

The 1997 amendments of the Individuals with Disabilities Education Act (IDEA) rmandates the Individual Education Plan (IEP) of students regardless of disability to include a BIP, presumably based on a conducted FBA [7]. Nevertheless, a salient question is whether this mandate has, or can, be implemented by IEP teams so that BIPs can be developed from the results of FBAs. For example, Conroy et al. [8] concluded that there has been a lack of trained personnel to conduct FBAs and develop BIPs. Couvillon et al. [9] found that educators who develop BIPs based on FBA data seldom received sufficient training on the use of these practices. In addition, Gable et al. [10] raised the issue of fidelity when IEP teams use results from FBAs to develop a BIP, and if this process is implemented incorrectly or inadequately that the challenging behaviors may not only persist but become more resistant to change. Finally, Blood and Neel [11] found that BIPs contained in the IEPs for students with ED tended to be more compliance" documents than positive treatment programs. In general, the process for developing BIPs from FBAs has been characterized as dismal [12].

Researchers have also investigated various aspects of the FBA and BIP process. For example, Cook et al. [13] examined the quality and substance within a BIP separate from the FBA. Their rationale was that the BIP served as a representation of the quality of the FBA data and that the former can be analyzed separately. They concluded that a vast majority of BIPs generated by "typical teams" (i.e., personnel without any special training in applied behavior analysis) were meaningfully insufficient. Several years later, Cook et al. [14] examined the association between the quality of BIPs, fidelity with which they were implemented, and student outcomes under typical educational situations without any contact with researchers. They found that BIPs containing evidence-based components were implemented with higher fidelity and resulted in better student outcomes than those lacking critical elements.

One important aspects of this literature that has received little study is the relation between disability category and the presence and quality of BIPs based on FBAs. Obviously students served under the ED category will have a BIP, presumably based on the results of FBAs, but students in other disability categories may also require this process and service. For example, according to the U. S. Department of Education (2016) [15] the number of students classified as having autism rose 69\% between 2004-2005 and 2013-2014 and students in the other health impaired (OHI) category increased approximately $43 \%$ while students with ED dropped $28 \%$. Consequently, the purpose of the present study was to examine the FBAs and BIPs generated from them for students in the ED, OHI, and autism categories of disability. The following variables were specifically assessed from student IEPs: (a) type of disability, (b) statements of behavioral need, (c) behavioral goals, (d) FBAs conducted, and (e) presence of a BIP.

\section{Method}

\section{Archival data}

Archival data from students' files consisting of a multidisciplinary team (MDT) evaluation and IEP document in grades $\mathrm{K}-12$ receiving special education services under the ED, OHI, and Autism categories were obtained from four Midwest school districts-one rural, two

${ }^{*}$ Correspondence to: John W Maag, Professor, Barkley Memorial Center, University of Nebraska-Lincoln, USA, Tel: 402-472-5477; Fax: 402-472-7697; E-mail: jmaag1@unl.edu

Received: May 09, 2018; Accepted: May 20, 2018; Published: May 25, 2018 
suburban, and one urban-ranging in size from 6,100 to 34,000 students. Table 1 contains demographic data by school district for SES and ethnicity. The files were stratified by the three disability categories prior to randomization.

The minimum sample size needed for each district was determined a priori using the $\mathrm{G}^{\star}$ Power 3 statistical power analysis [16]. Sample size was computed as a function of power level $1-\beta$, significance level $\alpha$, and the to-be-detected population effect size. Based on the variables to be examined, calculated sample size for each group was 83 participants. In order to account for attrition, an additional 40 files were examined. The total number of files examined was 310 . Table 2 presents additional demographics for the four districts by disability category.

\section{Variables coded}

A coding form was created to record information from the 310 files for the five variables under study: The following variables were specifically assessed from student IEPs: (a) type of disability, (b) statements of behavioral need, (c) behavioral goals, (d) FBAs conducted, and (e) presence of a BIP. File data were extracted and coded by the first author. Reliability data were collected by a licensed special education teacher who examined a random sample of $11.6 \%$ of the files. Reliabilities ranged from $.81 \%$ (IEP goals related to behavior) to $100 \%$ (presence of a BIP).

\section{Procedures}

First, files were examined to determine the number of students classified as ED, OHI, and Autism. Second, the number of files containing any combination of the remaining four variables (i.e., behavior need, behavioral IEP goal, FBA, BIP) were calculated by disability category. For example, a given file may contain a behavioral need and IEP goal but not the other three variables. The goal was to see if differences in components and combinations of components existed between each disability category.

\section{Data analysis}

Data were compiled and collated in terms of the number of files in which a student was identified as ED, OHI, and Autism. In addition, data were collected on how many students diagnosed as ADHD were served in any of those three categories. Descriptive data were obtained for the number of files that contained all possible combinations on the remaining four variables: (a) behavioral need, (b) behavioral IEP goal, (c) FBA, and (d) BIP. Finally, percentages of students in each disability category who had a "yes" response to each variable were calculated. Chi square statistics were calculated to examine whether the rates of behavioral needs, IEP goals, FBAs, and BIPs were significantly different between the three disability categories. The base number used when calculating the difference in IEP goals, FBAs, and BIPs was the number of students who had behavioral needs.

\section{Results}

Table 3 presents the data for the number of students identified as ADHD and Autism who were served in the three disability categories. The most consistent finding was that all but two students with autism were receiving services under the autism category $(\mathrm{N}=44)$. No students with ADHD were served under this category of disability. The vast majority of students with $\mathrm{ADHD}(\mathrm{N}=78)$ were served under the OHI category. Of the 22 students with ADHD being served under the ED category, only two were females.

Table 4 presents the number of files that had each possible combination of the following variables by category of disability: (a) behavioral need, (b) behavioral IEP goal, (c) FBA, and (d) BIP. The most consistent finding across categories was the number of files that had both a behavioral need and behavioral IEP goal. There were also six combinations across categories that had no cases: (a) BIP, (b) behavioral needs + FBA, (c) IEP goal + FBA, (d) IEP goal + BIP, (e) FBA + BIP, and $(\mathrm{d})$ behavioral needs + FBA + BIP. There were differences between categories on combinations of the variables. First, almost half (46\%) of files in the OHI category contained none of the codec variables. Of these 51, over half $(\mathrm{N}=28)$ were students with ADHD. Second, there were a relatively high percentage of files in the Autism category (36\%) that did not contain any of the variables. The ED category had a higher percentage $(25 \%)$ of files that contained behavioral needs + IEP goal + FBA than the two other categories. Third, there were a much higher percentage (34\%) of ED files that contained all four components.

Table 5 contains the number of files that had one or more of the four variables present. To determine differences in the four variables between disability categories, a series of Pearson Chi Square Tests of Independence analysis were computed. There were statistically significant differences between groups on all four variables: behavioral needs $(\chi 2[2]=52.367, \mathrm{p}<.025[\mathrm{p}=.000])$; behavioral goals $(\chi 2[2]=$ $20.013, \mathrm{p}<.025[\mathrm{p}=.000]) ;$ FBAs $(\chi 2[2]=34.532, \mathrm{p}<.025[\mathrm{p}=.000])$; and BIPs $(\chi 2[2]=14.909, \mathrm{p}<.025[\mathrm{p}=.001])$.

\section{Discussion}

The purpose of the present study was to examine the files of students being served under the ED, OHI, and Autism categories of disability to determine if there were differential rates in which there was documentation of (a) behavioral need, (b) behavioral IPE goal, (c) FBA, and (d) BIP. Results indicated that the ED category had the most files with documented behavioral needs, behavioral IEP, FBAs, and BIPs. A large percentage of files in the $\mathrm{OHI}$ and Autism categories contained none of the four variables. In terms of students with ADHD, out of the 100 files, $78 \%$ were being served in the OHI category and 36\% contained none of the four components. Expectedly, no students with ADHD were served under the Autism category while 22 were served under the ED category. Each of these findings is discussed along with implications for practice, methodological limitations, and areas for future research.

Table 1. SES and ethnicity by school type

\begin{tabular}{|l|c|c|c|}
\hline School district & Rural & Suburban & Urban \\
\hline Total student enrollment & 8,750 & 9,800 & 34,000 \\
\hline Percentage free/reduced lunch & $61 \%$ & $19 \%$ & 6,000 \\
\hline Ethnicity & & & $24 \%$ \\
\hline Caucasian & $51 \%$ & $86 \%$ & \\
\hline African-American & $3 \%$ & $5 \%$ & $83 \%$ \\
\hline Hispanic & $45 \%$ & $6 \%$ & $8 \%$ \\
\hline Asian/Pacific Islander & 1 & $3 \%$ & $5 \%$ \\
\hline
\end{tabular}


Table 2. Demographics by disability category

\begin{tabular}{|c|c|c|c|c|c|c|}
\hline \multirow[b]{2}{*}{ School district } & \multicolumn{2}{|c|}{ Emotional Disturbance } & \multicolumn{2}{|c|}{ Other Health Impaired } & \multicolumn{2}{|c|}{ Autism } \\
\hline & Male & Female & Male & Female & Male & Female \\
\hline Urban $(N=74)$ & 22 & 4 & 16 & 9 & 21 & 2 \\
\hline Elementary & 8 & & 8 & 3 & 13 & 0 \\
\hline Middle & 7 & 2 & 4 & 6 & 5 & 2 \\
\hline Secondary & 7 & 0 & 4 & 0 & 3 & 0 \\
\hline Suburban $(N=75)$ & 21 & 4 & 15 & 8 & 20 & 7 \\
\hline Elementary & 8 & 2 & 6 & 3 & 14 & 6 \\
\hline Middle & 5 & 0 & 6 & 1 & 3 & 1 \\
\hline Secondary & 8 & 2 & 3 & 4 & 3 & 0 \\
\hline Suburban $(N=90)$ & 25 & 5 & 22 & 8 & 27 & 3 \\
\hline Elementary & 12 & 1 & 8 & 4 & 15 & 3 \\
\hline Middle & 8 & 2 & 5 & 2 & 6 & 0 \\
\hline Secondary & 5 & 2 & 9 & 2 & 6 & 0 \\
\hline Rural $(N=73)$ & 8 & 1 & 31 & 3 & 24 & 6 \\
\hline Elementary & 4 & 0 & 14 & 1 & 12 & 3 \\
\hline Middle & 4 & 1 & 12 & 2 & 6 & 1 \\
\hline Secondary & 0 & 0 & 5 & 0 & 6 & 2 \\
\hline
\end{tabular}

Table 3. Number of students with ADHD and autism served in each disability category

\begin{tabular}{|c|c|c|c|c|c|c|}
\hline \multirow[b]{2}{*}{ School district } & \multicolumn{2}{|c|}{$\begin{array}{l}\text { Emotional disturbance } \\
(\mathrm{N}=91)\end{array}$} & \multicolumn{2}{|c|}{$\begin{array}{l}\text { Other health impaired } \\
(N=112)\end{array}$} & \multicolumn{2}{|c|}{$\begin{array}{l}\text { Autism } \\
(\mathbf{N}=107)\end{array}$} \\
\hline & ADHD & Autism & ADHD & Autism & ADHD & Autism \\
\hline \multicolumn{7}{|c|}{ Urban $(N=34,000)$} \\
\hline Male & 2 & 0 & 10 & 1 & 0 & 7 \\
\hline Female & 1 & 0 & 0 & 0 & 0 & 2 \\
\hline \multicolumn{7}{|c|}{ Suburban $(\mathrm{N}=\mathbf{9 , 8 0 0})$} \\
\hline Male & 7 & 1 & 9 & 0 & 0 & 6 \\
\hline Female & 0 & 0 & 5 & 0 & 0 & 0 \\
\hline \multicolumn{7}{|c|}{ Suburban $(\mathrm{N}=\mathbf{6 , 0 0 0})$} \\
\hline Male & 1 & 0 & 17 & 0 & 0 & 15 \\
\hline Female & 1 & 0 & 6 & 0 & 0 & 3 \\
\hline \multicolumn{7}{|c|}{ Rural $(\mathrm{N}=\mathbf{8 , 7 5 0})$} \\
\hline Male & 1 & 0 & 28 & 0 & 0 & 9 \\
\hline Female & 0 & 0 & 3 & 0 & 0 & 2 \\
\hline Totals & 22 & 1 & 78 & 1 & 0 & 44 \\
\hline
\end{tabular}

Table 4. Number of students with behavioral needs, behavior IEP Goals, FBA, and BIP

\begin{tabular}{|c|c|c|c|}
\hline Combination of Components & $\begin{array}{c}\text { Emotional Disturbance } \\
\text { N (\%) }\end{array}$ & $\begin{array}{l}\text { Other Health Impaired } \\
\text { N (\%) }\end{array}$ & $\begin{array}{l}\text { Autism } \\
\text { N (\%) }\end{array}$ \\
\hline None of the components & $1(1 \%)$ & $51(46 \%)$ & $39(36 \%)$ \\
\hline Behavioral needs & 0 & $12(11 \%)$ & $5(5 \%)$ \\
\hline IEP goal & 0 & $1(1 \%)$ & $1(1 \%)$ \\
\hline FBA & 0 & 0 & $1(1 \%)$ \\
\hline BIP & 0 & 0 & 0 \\
\hline Behavioral needs + IEP goal & $25(27 \%)$ & $31(28 \%)$ & $35(31 \%)$ \\
\hline Behavioral needs + FBA & 0 & 0 & 0 \\
\hline Behavioral needs + BIP & 0 & 0 & $3(3 \%)$ \\
\hline IEP goal + FBA & 0 & 0 & 0 \\
\hline IEP goal + BIP & 0 & 0 & 0 \\
\hline FBA + BIP & 0 & 0 & 0 \\
\hline Behavioral needs + IEP goal + FBA & $10(11 \%)$ & 0 & $1(1 \%)$ \\
\hline Behavioral needs + IEP goal + BIP & $23(25 \%)$ & $11(10 \%)$ & $15(14 \%)$ \\
\hline Behavioral needs + FBA + BIP & 0 & 0 & 0 \\
\hline IEP goal + FBA + BIP & $1(1 \%)$ & $1(1 \%)$ & 0 \\
\hline All 4 components present & $31(34 \%$ & $5(4 \%)$ & $7(7 \%)$ \\
\hline
\end{tabular}


Table 5. Number of students with behavioral needs, behavior IEP Goals, FBA, and BIP

\begin{tabular}{|l|c|c|c|}
\hline Files & $\begin{array}{c}\text { Emotional } \\
\text { Disturbance } \\
\text { (N \%) }\end{array}$ & $\begin{array}{c}\text { Other Health } \\
\text { Impaired } \\
\text { (N \%) }\end{array}$ & $\begin{array}{c}\text { Autism } \\
\text { (N \%) }\end{array}$ \\
\hline Behavioral need & $89(99 \%)$ & $59(53 \%)$ & $65(60 \%)$ \\
\hline Behavioral IEP goal & $89(99 \%)$ & $46(41 \%)$ & $57(52 \%)$ \\
\hline FBA & $42(47 \%)$ & $6(5 \%)$ & $8(7 \%)$ \\
\hline BIP & $55(61 \%)$ & $19(17 \%)$ & $25(23 \%)$ \\
\hline
\end{tabular}

Perhaps one of the most interesting findings was that over half the students with ADHD being served in the OHI category had none of the four variables reflecting the acknowledgement of behavioral issues or addressing them. Only $28 \%$ of the files included a behavior need and IEP goal. Although students with ADHD comprised 78\% of the sample in the OHI category, only $10 \%$ had any combination of factors that included a BIP. Yet, the difficulties these students have in paying attention, monitoring and adjusting activity levels, and poor impulse control poses substantial behavioral challenges for teachers [17]. Further, they not only present substantial behavioral challenges but also compromise over $65 \%$ of students receiving services in the $\mathrm{OHI}$ category of disability [17]. One possible explanation for the lack of IEPs addressing behavioral issues for students with ADHD may be the way this condition is conceptualized. There are powerful social forces committed to having ADHD viewed as a medical rather than behavioral condition [18].

It is similarly interesting that $36 \%$ of files of students being served in the Autism category did not have any of the four variables present and only $31 \%$ had a behavioral need and IEP goal, but no FBA or BIP. The lack of attention to functional behavioral assessment and behavioral interventions is curious for two reasons. First, applied behavior analysis (ABA) - on which functional assessment and behavioral supports are based-is the mainstay and evidenced-based approach for treating children with autism [19]. Second, researchers have found that challenging behaviors can be chronic and severe among children and adolescents with Autism Spectrum Disorders [20,21]. One possible explanation for this dearth may be that students with autism in the present sample simply did not display significant externalizing behaviors such as verbal and physical aggression and, instead, may have engaged in the more stereotypic behaviors characteristic of this population. Another reason may be that the behaviors characteristic of higher functioning students on the autism spectrum may simply appear "quirky" and not pose a threat to self or others.

A common concern across files in both the OHI and Autism categories was the lack of BIPs based on FBAs. This finding may not come as a surprise because in their study, Van Acker et al. [12] found that BIPs were not based on the identified function of behaviors determined during the FBA. It may be that the documented lack of training educators receive for conducting FBAs and developing BIPs $[8,9]$ sets up a situation in which FBAs and BIPs are perceived as separate and not unrelated practices. Of course, this supposition is contrary the evidence-base that BIPs plans based on the results of functional assessment are methodologically sound practice for students with ED, ADHD, and Autism [1,22,23]. However, as Forness [24] pointed out, there has traditionally been a lack of follow through from researchers identifying evidence-based practices to educators actually putting them into effect even though models exist to assist in this area.

Another common finding from all three categories was the preponderance or files that had a combination of behavioral needs and IEP goals, but no FBAs nor BIPs. Perhaps students in this group were perceived to have behavioral issues but ones that were not severe enough to warrant a formal FBA and BIP. This speculation may seem tacitly appealing for students in the Autism and OHI categories, but certainly not for students in the ED category who traditionally display the most disruptive behaviors of any other group of students [1].

In terms of actual practice, schools need to be more cognizant that students with ADHD now constitute the majority being served in the $\mathrm{OHI}$ category. Furthermore, many of these children spend the majority of their time in the general education classroom $[17,25]$. Consequently, both special education and general education teachers are likely to work with these students. It is important for them to have basic information about the interventions and accommodations from which students with ADHD will benefit. The BIP is a vehicle to ensure techniques are accessible and that special education teachers can work collaboratively with general education teachers.

The lack of BIPs being based on FBAs also permeated the files in the Autism category. Yet experts agree that the primary methods for reducing challenging behaviors of students with autism are based on results of FBAs [23]. Love et al. [26] examined FBAs from archival data of children with ASD being treated at an outpatient clinic and found that they lacked socially appropriate responses to access positive reinforcement or that their environment did not provide sufficient social reinforcement. These areas would be more easily identified and treated if it became common practice to routinely conduct FBAs on students with ASD. In addition, Gable, Hendrickson, and Van Acker (2001) [10] identified several factors that affect the fidelity of BIPs in relation to FBA information to help guide educators: (a) understanding the role of contextual variables that maintain challenging behavior, (b) school personnel possessing knowledge and acceptance of evidencebased interventions, (c) identifying appropriate replacement behaviors, and (d) identifying standards to evaluate behavior change. It is possible that educators do not have the expertise to address all of these areas without appropriate consultation. Regardless, it is important for educators to understand that simply engaging in activities to generate a hypothesis is insufficient. Those hypotheses must be tested and verified in order to develop effective BIPs.

There are several limitations to the results of the present study. First, the participating school districts came from a Midwestern state and results may not readily generalize to other regions of the country. Consequently, future research may focus on larger samples over a more geographically diverse area. Second, because archival data were used, it was impossible to determine the expertise of personnel who documented behavioral needs and IEP goals focusing on behavior. In addition, many school districts have computerized and archived IEP goals and objectives that may not be modified nor include documentation of standards and assessment (Thompson, Thurlow, Esler, \& Whetstone, 2001) [27]. This variable and others such as differences in school policy and level of staff training should be the focus of additional research. Regardless, there is a clear need for school districts to implement policies and procedures for ensuring that students with ADHD who are served under the $\mathrm{OHI}$ category of disability and students served in the Autism category have their behavioral needs addressed and functional relevant interventions developed, implemented, and monitored [28,29].

\section{References}

1. Kauffman JM, Landrum TJ (2009) Characteristics of emotional and behavioral disorders of children and youth (9thedn), Upper Saddle River, NJ: Pearson.

2. Blair KC, Umbreit J, Dunlap G, Jung G (2007) Promoting inclusion and peer participation through assessment-based intervention. Topics in Early Childhood Special Education 27: 134-147. 
3. Dunlap G, Kern L, dePerczel M, Clarke S, Wilson D, et al. (1993) Functional analysis of classroom variables for students with emotional and behavioral disorders. Behavioral Disorders 18: 275-291.

4. Martin CA, Drasgow E, Halle JW, Brucker, JM (2005) Teaching a child with autism and severe language delays to reject: Direct and indirect effects of functional communication training. Educational Psychology 25: 287-304.

5. Mueller MM, Nkosi A (2007) State of the science in the assessment and management of severe behavior problems in school settings: Behavior analytic consultation. The International Journal of Behavioral Consultation and Therapy 3: 176-202.

6. Kern L, Hilt AM, Gresham F (2004). An evaluation of the functional behavioral assessment process used with students with or at risk for emotional and behavioral disorders. Education and Treatment of Children 27: 440-452.

7. Maag, JW, Katsiyannis A (2006) Behavioral intervention plans: Legal and practical considerations for students with emotional and behavioral disorders. Behavioral Disorders 31: 348-362.

8. Conroy M, Katsiyannis A, Clark D, Gable RA, Fox JM (2002) State Office of education Practices: Implementing the IDEA disciplinary provisions. Behavioral Disorders 27: 98-108.

9. Couvillon MA, Bullock LM, Gable RA (2009) Tracking behavior assessment methodology and support strategies: A national survey of how schools utlize functional behavioral assessments and behavior intervention plans. Emotional \& Behavioral Difficulties 14: 215-228.

10. Gable RA, Hendrickson JM, Van Acker R (2001) Maintaining the integrity of FBAbased interventions in schools. Education \& Treatment of Children 24: 248-260.

11. Blood E, Neel RS (2007) From FBA to implementation: A look at what is actually being delivered. Education and Treatment of Children 30: 67-80.

12. Van Acker R, Boreson L, Gable RA, Potterton T (2005) Are we on the right course? Lessons learned about current FBA/BIP practices in schools. Journal of Behavioral Education 14: 35-56.

13. Cook CR, Crews SD, Wright DB, Mayer GR, Gale B, et al. (2007) Establishing and evaluating the substantive adequacy of positive behavioral support plans. Journal of Behavioral Education 16: 191-206.

14. Cook CR, Mayer GR, Browning Wright D, Kraemer B, Wallace MD, et al. (2010) Exploring the link among behavior intervention plans, treatment integrity, and student outcomes under natural educational conditions, Journal of Special Education 46: 3-16.
15. U.S. Department of Education (2016) Digest of education statistics. Washington, DC: National Center for Educational Statistics.

16. Faul F, Erdfelder E, Buchner A, Lang AG (2009) Statistical power analyses using G*Power 3.1: Tests for correlation and regression analyses. Behav Res Methods 41: 1149-1160. [Crossref]

17. Schnoes C, Reid R, Wagner M, Marder C (2006) ADHD among students receiving special education services: A national survey. Exceptional Children 72: 483-496.

18. Reid R, Maag JW, Vasa SF (1994) Attention-deficit hyperactivity disorder as a disability category: A critique. Exceptional Children 60: 198-214.

19. Ringdahl, JE, Kopelman T, Falcomata TS (2009) Applied behavior analysis and its application to autism and autism related disorders. In: Matson JL (Ed.), Applied behavior analysis for children with autism spectrum disorders (pp. 15-32). New York, NY: Springer Science.

20. Jang J, Dixon DR, Tarbox J, Granpeesheh C (2011) Symptom severity and challenging behavior in children with ASD. Research in Autism Spectrum Disorders 5: 1028-1032.

21. Matson JL, Mahan S, Hess JA, Fodstad JC, Neal D (2010) Progression of challenging behaviors in children and adolescents with autism spectrum disorders as measured by the Autism Spectrum Disorders-Problem Behaviors for Children (ASD-PBC) Research in Autism Spectrum Disorders 4: 400-404.

22. Maag JW, Reid R (1994) Attention-deficit hyperactivity disorder: A functional approach to assessment and treatment. Behavioral Disorders 20: 5-23.

23. Scheuermann B, Webber J (2002) Autism: Teaching does make a difference. Belmont, CA: Wadsworth/Thomson Learning.

24. Forness SR (2005) The pursuit of evidence-based practice in special education for children with emotional or behavioral disorders. Behavioral Disorders 30: 311-330.

25. Reid R, Maag JW, Vasa SF, Wright G (1994) Who are the children with ADHD: A school-based survey. Journal of Special Education 28: 117-137.

26. Love JR, Carr JE, Leblanc LA (2009). Functional assessment of problem behavior in children with autism spectrum disorders: A summary of 32 outpatient cases. $J$ Autism Dev Disord 39: 363-372. [Crossref]

27. Thompson SJ, Thurlow ML, Esler A, Whetstone PJ (2001) Addressing standards and assessments on the IEP. Assessment for Effective Intervention 26: 77-84.

28. Reid R, Maag JW (1997) Attention deficit hyperactivity disorder: Over here and over there. Educational and Child Psychology 14: 10-20.

29. Zirkel PA (2011) State special education laws for functional behavioral assessment and behavior intervention plans. Behavioral Disorders 36: 262-278.

Copyright: (C2018 Serfass C. This is an open-access article distributed under the terms of the Creative Commons Attribution License, which permits unrestricted use, distribution, and reproduction in any medium, provided the original author and source are credited. 